\title{
CONFLITO DE LEIS MARÍTIMAS: QUESTÕES PRÉVIAS*
}

\author{
Vicente Marotta Rangel \\ Professor Catedrático aposentado da Faculdade de Direito \\ da Universidade de São Paulo
}

\begin{abstract}
Resumo:
Louvável é a distinção entre, de um lado, a unificação internacional de regras de conflito e, de outro lado, a uniformidade internacional de regras materiais. Na realidade, porém, número crescente de convenções destinadas à uniformidade internacional de regras materiais contém normas de direito colisional. Tal ocorre com a Convenção das Nações Unidas sobre o Direito do Mar (1982) e a Convenção sobre Condições de Registro de Navios (1986). Uma das razões dessa ocorrência reside na existência de áreas de interesse comum entre normas materiais e normas colisionais. Uma dessas áreas é da nacionalidade e, no caso das Convenções citadas, a da nacionalidade dos navios. É sobre navios, seu conceito, sua classificação e, sobretudo, sobre nacionalidade de navios assim como critérios e motivos estabelecidos para a determinação dessa nacionalidade que 0 artigo se propõe examinar. Para o exame desse último tópico, se invocam casos marcantes de jurisprudência internacional.
\end{abstract}

\begin{abstract}
:
Distinction made between the unification of substantive laws and the unification of conflict laws has deserved large support. International law doctrine has taken this distinction as a preliminary basis. In practice, however, international agreements related to substantive issues include conflict of laws rules. Examples of these agreements are the United Nations Convention on the Law of the Sea (1982) and the United Nations Convention on Conditions for Registration of Ships (1986). One of the reasons for the inclusion is the identify or similarity of subjects covered either by substantive or conflict rules. This occurs for instance in relation with ships, its definition and classification and, above all, with its nationality. To the latter question (nationality of ships) the article addresses more careful attention. It refers to some leading cases decided by international courts.
\end{abstract}

Unitermos: condições de registro de navios.

* Estudo escrito para livro em homenagem a Haroldo Valladão, editado na Venezuela. 
Sumário:

I - Introdução

II Conceito de navio

III - Classificação dos navios

IV - Conceito de nacionalidade dos navios

V Regras sobre nacionalidade dos navios

VI - A questão do vínculo substancial

VII - Observações finais

\section{Introdução}

1. Em seu clássico e abrangente programa de ensino de Direito Internacional Privado, Haroldo Valladão dá particular atenção à ruptura da uniformidade legislativa marítima, processada a partir do século XVII. Consolidou essa ruptura a promulgação do Código do Comércio da França, de 1808, que, tratando do Direito marítimo no Livro II, alcançou larga repercussão na Europa Ocidental e na América Latina. Todavia, não há confundir - preceitua a esse respeito o insigne jurista duas tarefas distintas: de um lado, a unificação internacional de regras de conflito; e, de outro lado, a uniformidade internacional de regras materiais. Ao louvar a orientação do Institut de Droit International que, nas sessões de Bruxelas de 1885 e de Lausanne de 1888 , havia separado as duas tarefas, Haroldo Valladão reconhece, embora lamente, que em um número crescente de convenções destinadas a unificar normas materiais de Direito marítimo, se encontrem normas de direito colisional. ${ }^{1}$

2. É o que ocorre com a recente Convenção das Nações Unidas sobre o Direito do Mar. Conquanto seja o seu escopo primordial alcançar a uniformidade material desse direito, a Convenção contém algumas regras de solução de conflitos espaciais. $\mathrm{O}$ cultor do Direito Internacional Privado não as desconhece. Elas constam dos arts. 21, 27 e 28 , inseridas na parte sobre mar territorial e concernentes, respectivamente, às leis e regulamentos do Estado costeiro relativos à passagem inocente e à distribuição de competências entre o Estado costeiro e o Estado do pavilhão em matéria penal e civil. Inscrevem-se nos arts. 56 e 58 , atinentes

1. Haroldo Valladão, Direito Internacional Privado, v. III, Rio-São Paulo, Freitas Bastos, 1978, pp. 51-3. 
respectivamente aos direitos do Estado costeiro e do Estado de pavilhão na zona econômica exclusiva. Figuram também, de um lado, nos arts. 94, 98, 99, 100, 108 , 109 e 118 e, de outro lado, nos arts. 87 e 112, concernentes respectivamente às obrigações e direitos do Estado do pavilhão no alto-mar. Inserem-se finalmente nos arts. 217,218 e 221, atinentes respectivamente aos poderes e direitos do Estado do pavilhão, do Estado do porto e do Estado costeiro.

3. Em parte, a razão pela qual grande número de tratados internacionais contempla concomitantemente normas de direito material e de direito colisional reside na dificuldade cada vez mais intensa de, contemporaneamente, separar num mesmo instrumento, de modo categórico, regras pertencentes aos dois ramos do Direito Internacional: Privado e Público. ${ }^{2}$ A doutrina tem convivido pragmaticamente com ambos os direitos, ${ }^{3}$ embora por vezes se tenha proposto conciliar ou transcender essa dicotomia. Tal propósito não foi estranho a Haroldo Valladão, cujo rigor metodológico o induzia a assumir posições ortodoxas como a acima referida, para o fim de demarcar e profundar o âmbito do Direito Internacional Privado de que foi mestre consagrado, tanto quanto o foi igualmente do Direito das gentes. $^{4}$

2. Sobre as relações entre ambos os direitos, vide extensa bibliografia in François Rigaux, Droit Public et Droit Privé dans les Relations Internationales, Paris, A. Pedone, 1977, pp. 415-6. Cf. igualmente Konrad Zweigter, Droit International Privé et Droit Public, Revue Critique du Droit International Privé, 1965, t. 54, pp. 32-91; Adolf F. Schnitzer, Les relations entre le Droit International Privé et le Droit International Public, Symbolae Garcia Arias, Temis, pp. 33-36, Universidad de Zaragoza, 1973-1974, pp. 583-603; Giuseppe Sperduti, Droit International Privé et Droit Public étranger, Journal du Droit International, 1977, n. 1, pp. 1-15; Pierre Mayer, Droit International Privé et Droit International Public sous l'angle de la notion de compétence, Revue Critique de Droit International Privé, 1979, t. 68, pp. 1-29, pp. 350-88 e pp. 537-83; e Joe Verhoeven, Droit International Public et Droit International Privé: où est la différence?, Archives de Philosophie due Droit, t. 32, 1987, pp. 23-34.

3. Vide verbi gratia $\mathrm{o}$ artigo de Brigitte Stern, Quelques observations sur les règles internationales relatives à l'application extraterritoriale du droit (AFDI, 1986, pp. 7-52), cuja parte final consiste no exame das regras do Direito Internacional tanto Público quanto Privado concernentes a conflitos de competência de correntes da aplicação extraterritorial do direito. De ambos os direitos há também constância no exame procedido por Richard B. Lillich e Burns H. Weston, de 126 acordos bilaterais, na obra por ambos escrita: International Claims: Their Settlement by Lump Sum Agreements, publicada pela University Press of Virginia (Charlottesville).

4. Entre os dois ramos do direito, o qualificativo internacional está presente, embora, como assinala Verhoeven, visando a duas realidades totalmente distintas: "if désigne tantôt l'ordre juridique particulier qui organise les relations entre Etats, tantôt l'objet particulier de règles par lesquelles chaque Etat tente d'appréhender des relations qui le débordent" (ob. cit., p. 24). 
A concomitância de regras materiais e colisionais no mesmo instrumento convencional se deve também à existência de áreas de interesse comum a ambas essas regras. Nas concernentes quer ao Direito Internacional Privado marítimo, quer ao Direito do Mar, uma dessas áreas é, sem dúvida, a da nacionalidade dos navios. Cada Estado determina as condições de outorga de pavilhão e de registro dos navios. Até recentemente, essa competência era discricionária. Mas mesmo hoje, quando essa competência é restringida por normas internacionais, conflitos de leis têm ocorrido. Da relevância e contemporaneidade desse tema comum ao Direito das gentes e ao Direito Internacional Privado são testemunhos das duas convenções internacionais concluídas no curso da presente década, ambas patrocinadas pelas Nações Unidas: sobre o Direito do Mar, assinada a 10 de dezembro de 1982; e sobre Condições de Registro de navios, adotada por consenso a 7 de fevereiro de 1986.

A assinatura daquela Convenção se deu em Montego Bay, na Jamaica, por ocasião da sessão de encerramento da III Conferência das Nações Unidas sobre o Direito do Mar. A sessão teve dois propósitos: o de propiciar a assinatura da Ata Final da Conferência e o de dar início à assinatura do novo tratado sobre Direito do Mar. Chegava-se então ao término de longa e áspera jornada que remontava a 1968, quando se constituiu a Comissão dos Fundos Oceânicos, órgão embrionário da Conferência iniciada em 1973 com sessão de ordem processual, em New York.

A Convenção tem sido considerada - após a Carta das Nações Unidas o mais importante tratado internacional até agora celebrado. Apesar de sua extensão considerável pois abrange mais de 400 artigos e não obstante sua extrema complexidade, ela grangeou apoio mui significativo da comunidade internacional, bastando notar que desde o primeiro dia passou a contar fato inédito na história das convenções com 119 assinaturas, número esse que, dois anos mais tarde, no dia do encerramento das mesmas, ascendeu a 159. Sem dúvida, a Conferência teve uma duração excepcional: quinze anos de trabalhos contínuos, dos quais seis dedicados a trabalhos preparatórios e nove à elaboração de Convenção (que se estendeu ao longo de onze sessões). Esse período prolongado não significou fraqueza e indecisão, mas antes a emergência de causas diferentes e complexas. A primeira delas foi a inexistência de um anteprojeto de convenção; a segunda está relacionada com a amplitude e a diversidade sem paralelo dos interesses em jogo; a terceira concerne a técnicas específicas dessas negociações, do package deal ao consenso assim como à 
redação e revisão de textos sucessivos. ${ }^{5}$ Enquanto a Conferência "representa a mais ambiciosa, abrangente e complexa negociação internacional na história" 6 o tratado dela resultante tem sido qualificado de "uma constituição para os oceanos" 7

Adotada por consenso por 109 Estados seis anos depois da Convenção sobre o Direito do Mar, ao término de uma conferência de plenipotenciários convocada pela Assembléia Geral das Nações Unidas, e que abrangeu quatro sessões em Genebra (a primeira das quais iniciada a 16 de julho de 1984), a segunda Convenção tem caráter mais específico, dizendo respeito a "bandeiras de conveniência" e visando assegurar a existência de um "vínculo substancial", e exercício efetivo de jurisdição e controle pelo Estado do pavilhão. ${ }^{9}$

\section{II - Conceito de Navio}

4. O tema da nacionalidade dos navios requer, por seu turno, o exame prévio do conceito de navio. Trata-se, como se sabe, de palavra derivada do latim navigium que, originariamente, designava toda construção apta a percorrer águas as mais diversas. Navem accipere debemus, sive marinam, sive fluviatilem, sive in aliquo stagno naviget sive schedia sit. ${ }^{10} \mathrm{E}$ palavra consagrada na terminologia jurídica, em correspondência com as palavras navire, buque e ship, respectivamente francesa, espanhola e inglesa, ${ }^{11}$ destinadas a exprimir uma noção conhecida mas

5. Sem dúvida, essas técnicas não eram então inéditas, mas o seu aspecto marcante residia no fato que elas foram então utilizadas em conjunto pela primeira vez e de forma sistemática e integrada.

6. Robert D. Eudis, Procedures and techniques of multinational negociation: the LOS III model, Virginia Journal of International Law, 1977, v. 17, n. 2, p. 217.

7. John King Gamble Jr., Status of the 1982 Convention on the Law of the Sea, Marine Policy Reports, University of Delaware, Center for the Study of Marine Policy, julho de 1988, v. 10, n. 3, p. 1.

8. Relación autêntica (espanhol), lien substantiel (francês) e genuine link (inglês).

9. Djamchid Momtaz, La Convention des Nations Unies sur les Conditions d'Immatriculation des Navires, AFDI, 1986, pp. 715-35 e Geoffrey Marston, The UN Convention on Registration of ships, Joumal of Trade Law, pp. 575-80.

10. D.14.1.1.6.

11. Observe-se que os textos espanhol e francês da Convenção das Nações Unidas sobre o Direito do Mar usam sempre da mesma palavra (buque e navire), enquanto o texto inglês oferece alguma variante: vessel ao lado de ship. Cf. Tullio Treves, La Navigation, in Traité du Droit de la Mer, (Dupuy-Vignes), Paris-Bruxelles, 1985, p. 693-4. 
variável e flexível. Ao versar outras questões sobre navios, ${ }^{12}$ o Direito Romano serviu de inspiração a leis subsequientes, à medida que a comunicação marítima, mais concentrada no Mediterrâneo, cresceu e se ampliou a outros espaços.

Estendendo-se o mar por cerca de três quartas partes da superfície de nosso planeta, ressalta de imediato a significação do veículo de comunicação que por ele transita: o navio. É notória a contribuição para este direito de controvérsias referentes às embarcações marítimas. A solução de tais controvérsias exigiu a elucidação de princípios e normas que influíram decisivamente no desenvolvimento de capítulos os mais diversos do Direito Internacional: Santa Catarina, no da polêmica da liberdade dos mares; Alabama, no do estatuto da neutralidade; Montijo, no das relações entre normas internas e internacionais; Lotus, no da competência criminal em alto-mar; Wimbledon, no da responsabilidade internacional dos Estados; Sapphire, no da representação estatal; Schooner Exchange, no da imunidade estatal; Caroline, em matéria de legítima defesa...

5. Sobretudo a partir do começo de nosso século, tratados internacionais têm perfilhado definições ad hoc de navios, ou seja, em razão do objetivo por elas colimado. Assim o fez a convenção relativa à transformação de navio de comércio em navio de guerra, celebrada na Segunda Conferência da Paz de Haia de 1907, nos termos da qual a palavra "navio" se aplica a navios de recreio e de comércio e não a navios de guerra. Segundo a Convenção de Bruxelas sobre Assistência e Salvamento, de 1910, o termo "navio" (ship) (buque) é empregado em seu mais amplo sentido, "which floats on the water serving to the transport of persons or goods or employed to commercial, industrial, scientific and technical operations or to sports" 13 Também em sentido amplo, o termo é empregado em convenções internacionais de trabalho, o que se compreende pelo desejo de se entender ao máximo a proteção dos trabalhadores do mar: vejam-se, por exemplo as convenções n. $7 / 1920$, n. $15 / 1921$, n. $16 / 1921$, n. $22 / 1926$ e n. 58/1936. Igualmente ocorre na Convenção de Bruxelas de 1924 sobre conhecimento de embarque (bill of lading) e na Convenção de Genebra de 1930 sobre colisão em águas interiores. Sentido restrito do conceito de navio se encontra, por outro lado, em convenções como a referente ao Regime Internacional de Portos Marítimos, de 1923, a qual não é

12. Vide George Lazaratus, The definition of ship in national and international law, Revue Hellénique de Droit International, juillet-décembre 1969, p. 63.

13. Procès Verbaux de la Conférence Maritime à Bruxelles, 1905-1910, t. II, pp. 129-130. 
aplicável nem a navios de guerra nem a embarcações de pesca; ou como a Convenção sobre Prevenção de Poluição do Mar por Óleo, de 1954 (emendada em 1962) a qual se destina apenas, como é compreensível, a navios que empregam ou transportam petróleo.

6. Se bem constem dessas convenções definição ad hoc de navio, houve tentativas de conceituá-lo em tese, independentemente de vinculação que pudesse ter com o objetivo particular deste ou daquele tratado. Essas tentativas ocorreram em época anterior ao aparecimento de convenções internacionais que colimassem fazêlo. Assim, Pardessus, no começo do século passado, declarava em sua Collection des Lois Maritimes, publicadas em Paris, de 1828 a 1845, e reproduzidas cerca de um século depois em fac-símile (Turim, 1959), que o navio, termo genérico, “designe les embarcations destinées è transporter par mer des personnes ou marchandises quels que soient les noms variés qu'on leur donne dans les diverses législations" 14 Gilbert Gidel foi mais minucioso ao dizer que "le navire de mer de surface n'est pas seulement tout engin flottant, mais tout engin, quelles que soient ses dimensions et sa dénomination, apte à se mouvoir dans les espaces marins (à l'exclusion des autres milieux) avec l'armement et l'équipage qui lui sont propres..." 15 Para A. Thomazi, "un navire est un flotteur capable de mouvement, construit pour transporter des personnes ou des choses, ou les deux" 16

Há quase quatro décadas J. P. François em seu relatório de 17 de março de 1950, apresentado à Comissão de Direito Internacional, após lembrar que o primeiro tema a considerar era o da definição de navio, ${ }^{17}$ reportou-se à formulada por Gidel. Preferiu a Comissão, como se sabe, evitar qualquer definição a respeito, a qual não consta de nenhum dos tratados negociados em Genebra, 1958. Ela não consta, igualmente, da Convenção das Nações Unidas sobre o Direito do Mar, de 1982. Diversas são as razões do silêncio dessas Convenções: ser dispensável definir o que é obvio; ser a definição fonte de controvérsias; estar o objeto definido sujeito a modificações impostas pelo constante processo tecnológico. ${ }^{18}$

14. Apud George Lazaratus, ob. cit., p. 63.

15. Le Droit International Public de la Mer, v. I, 1932, p. 70.

16. Les Navires, Paris, 1950, PUF, Que sais-je, p. 5.

17. Doc. A/CN.4/17. Yearbook of International Law Commission, v. II, p. 38.

18. Foi esse terceiro motivo que induziu, no dizer de Albert de La Pradelle, os autores da Convenção de Chicago a também abster-se de definir o termo "aeronave". Eles desejavam permitir a 
Da longa série de tratados internacionais que contêm definição ad hoc de navios, o último celebrado é a Convenção das Nações Unidas sobre condições de registro de navios, de Genebra, de 07 de fevereiro de 1986. Para os propósitos dessa convenção o termo ship - diz o art. 2 - "means any self-propelled sea-going vessel used in international seaborne trade for the transport of goods, passengers, or both with the exception of vessels less than 500 gross registered tons." 19

7. Tendo por base a definição de navio proposta por François, a qual está em sintonia com a de Gidel, verifica-se constituir elemento essencial do navio ser ele um engenho apto a locomover-se nos espaços marítimos. Não necessita de estar efetivamente a singrar mares, podendo ser destinado à comunicação e transporte lacustre e fluvial. Mas deve ter aptidão para locomover-se nos espaços marítimos, condição essa que aliás é sufragada em convenções internacionais, de que é exemplo a de Bruxelas, de 25 de agosto de 1924 sobre conhecimento. Essa aptidão de se locomover e o fato de navegar lhe são essenciais. Movimentar-se é o seu fadário. Se reduzido a pontão, ou transformado em escola de marinheiros, mas imobilizado no porto, perde o seu estado, deixa de ser navio. "Ou navega ou não é navio". 20 Navegação implica flotación y desplazamiento, pero substancialmente gobierno y maniobra. Portanto não são navios, exemplifica Gonzáles Lebrero, ${ }^{21}$ "las boyas, los cascos hundidos, los diques flotantes, las grúas flotantes, los hidroaviones, los estacionários de práctivos, los pontones fondeados en caráter permanente...".

Para alguns autores como H. Meyers ${ }^{22}$ e Yves van der Mensbrugghe, ${ }^{23}$ afigura-se supérflua a presença de armamento $^{24}$ e de equipagem próprios. Parece-

extensão ulterior desse termo a aparelhos ainda desconhecidos em sua época (Revue générale de l'air, 1946, p. 109).

19. Hoje há petroleiros que ultrapassam 500 mil toneladas. Cf. Christian Philip, Souveraineté, intérêts économiques et coopération dans le droit international des transports. Aspects Actuels du Droit International des Transports, (Colloque du Mans de la Société Française pour le Droit Intemational), Paris, Pedone, 1981, p. 3.

20. Waldemar Ferreira, Tratado de Direito Comercial, v. 12, São Paulo, Saraiva, 1964, p. 376. Nesse ponto, é a lição clássica de Geomes Ripert, Droit Maritime, I, Paris, Rousseau et Cie, p. 276. 80.

21. Gonzáles Lebrero, Manual de Derecho de la Navegación, Buenos Aires, Depalma, 1972, p.

22. The Nationality of Ships, Haia, Nijhoff, 1967, p. 9-14.

23. Réflexions sur la Définition du Navire dans le Droit de la Mer. Actualité du Droit de la Mer, Societé Française pour le Droit International, Colloque de Montpellier, Paris, Pedone, 1973, p. 64.

24. Armamento é o apetrechamento do navio. Equipagem é o pessoal de serviço nele embarcado. Significa a tripulação, embora "equipagem" fosse termo outrora empregado para designar o 
nos, todavia, ser este um elemento relevante desde que por armamento e equipagem se pretenda dizer comunidade, conjunto de pessoas, pois, como dizia Ortolan, ao se referir aos navios de comércio, elas são "l'habitation mobile des sociétés particulières" $25 \mathrm{O}$ navio é, de fato, quer de comércio, quer de guerra, um engenho apto a singrar espaços marítimos mas com pessoas que nele se encontrem, o que exige, por sinal, por motivo da efetividade da própria navegação, uma certa ordem e coordenação. Integra, assim, o navio, como elemento que lhe é básico, uma "comunidade organizada", ou seja, uma tripulação que se orienta por certas normas e por alguma espécie de comando.

8. Tal noção nos ajuda a enfrentar o problema crucial da natureza jurídica do navio. Obviamente ele é uma cousa e sobre ele incidem direitos reais. É difícil admitir, por esse motivo, tenha ele nacionalidade. ${ }^{26}$ Forçoso é convir, porém, ser ele uma cousa especial precisamente por motivo do elemento que lhe é básico, a "comunidade organizada", razão pela qual ele parece revestir-se de vida própria. Como que nasce, adquire nome, registra-se, tem domicílio, sexo (man-or-war), declina, morre. "Des comportements sont atribués au navire, des obligations lui sont imposées comme s'il s'agissait d'une personne; il explore, il pêche, il combat, il commerce, il est astreint à une discipline, il s'expose à des sanctions..., toutes expressions qu'il ne viendrait à l'idée de quiconque à appliquer à une automobile, par exemple" ${ }^{27}$ Chega-se por isso a ter a impressão de ter o navio personalidade jurídica, de ser sujeito de direito. Nos tribunais de alguns países, como o Reino Unido, não são citados para comparecer nem o capitão nem o proprietário dos navios para contestarem uma ação, mas o próprio navio como se este pudesse ser juridicamente responsável. Atente-se para a linguagem dos tratados internacionais. Segundo a Convenção de Bruxelas sobre abordagem, algumas expressões personificam os navios. Nela há menção à abordagem que se deve à falta cometida

aparelhamento total da embarcação (J.C. Sampaio de Lacerda, Curso de Direito Privado da Navegação, I, $2^{2}$ ed., Rio de Janeiro, Freitas Bastos, 1974, p. 93).

25. Règles Internationales et Diplomatie de la Mer, Paris, I, $4^{\mathrm{a}}$ ed., 1864, p. 180.

26. É significativa aliás, a intervenção de Roger Pinto no curso da $11^{\text {a }}$ Sessão da Assembléia Geral, perante a $6^{\mathbf{a}}$ Comissão, em que ele pleiteou a supressão no projeto de resolução então debatido, de "toda alusão a uma pretendida nacionalidade de navios" (Apud J.M. Roux, Les Pavillons de Complaisance, Paris, LGDJ, 1961, p. 55).

27. François-Michel Fay. La nationalité des navires en temps de paix. RGDIP, 1973, p. 1007. Cf. Também no mesmo sentido, Antonio Alves Câmara, Ensaio sobre as Construções Navais Indígenas no Brasil, 2² ed., São Paulo, Companhia Editora Nacional, 1937, p. 17-8. 
por um dos navios (art. 3) e à responsabilidade do transportador e do navio (art. 4). Para a Convenção das Nações Unidas sobre o Direito do Mar (1982) "los buques navegará com el pabellón de un solo Estado" e não poderão "cambiar de pabellón durante un viaje ni en una escala..." (art. 92, $\left.\S 1^{\circ}\right) .^{28}$ Gozam eles muitas vezes de imunidade. $^{29}$ Tal impressão, embora divorciada da realidade fatual dos ordenamentos jurídicos, se compreende por motivo da íntima associação existente entre o navio e as pessoas humanas que compõem a sua tripulação. Compreende-se também por força dessa mesma associação o emprego do termo "nacionalidade dos navios" na ordem jurídica interna e internacional com o entendimento de que essa expressão possui apenas "uma analogia mais ou menos longínqua com a nacionalidade das pessoas físicas" 30

\section{III - Classificação dos Navios}

9. A temática da "nacionalidade dos navios" está intimamente conexa com a da classificação dos navios. Sejam estes privados ou mercantes, tende a aumentar o índice de conflito de leis marítimas; sejam estes públicos ou de guerra, tende esse índice a diminuir. Se se buscar, por outro lado, a origem do conceito de nacionalidade dos navios, verificar-se-á prioridade cronológica dos navios públicos (de guerra) em relação aos mercantes. Quanto àqueles era relativamente fácil vinculá-los a determinado Estado. Quanto a estes, dúvidas profundas subsistiam, a começar pelo fato de que, até o final do século XVII, os navios privados (mercantes) eram considerados como dependentes apenas dos súditos que os possuíssem, fato esse que favorecia o arbítrio das potências em determinar os navios qualificados de neutros em época de conflitos armado. ${ }^{31}$

10. Essa classificação tradicional, a de navios públicos (de guerra) e mercantes (privados), baseada na qualidade do proprietário do navio, ${ }^{32}$ ficou de certo

28. Redação similar é a do art. $6^{\circ}, \S 1^{\circ}$, da Convenção sobre o Alto Mar (1958).

29. Cf. arts. 8 e 9 de Convenção sobre o Alto Mar (1958) e arts. 95 e 96 da Convenção das Nações Unidas sobre o Direito do Mar (1982).

30. François-Michel Fay, ob. cit., p. 1006.

31. Cf. Adam Boleslaw Boczek. Flags of Convenience: an International Legal Study, Cambridge, Harward University Press, 1962, pp. 94 e ss.

32. Cf. Marcel Sibert, Traité de Droit International Public, I, Paris, 1951, p. 939. 
modo abalada a partir do término da Primeira Guerra Mundial e, mais particularmente, da ascensão do partido comunista russo. Vingou finalmente o critério proposto baseado na destinação da utilização do navio.

Esboçada por Pitt Corbett em 1922, em seu Leading cases on international law (p. 270), ${ }^{33}$ a nova classificação ficou motivada pela necessidade de limitar os privilégios de imunidade de jurisdição de que passariam a se beneficiar os países de regime integralmente socialista. Tais privilégios, deferidos de início a navios de guerra, como o admitiu a sentença da Suprema Corte dos Estados Unidos, de 1812, na controvérsia "The Exchange" v. MacFaddon, haviam sido estendidos a todo navio de Estado. A classificação baseada no critério subseqüente se inseriu na "Convenção internacional para a unificação de certas regras concernentes às imunidades dos navios de Estado" (1926) e se consagrou no Regulamento sobre "le régime des navires de mer et de leurs équipages dans les ports étrangers en temps de paix" ${ }^{34}$ aprovado pelo Institut de Droit International em sua sessão de 1928, de Estocolmo. Consoante essa classificação, duas são as categorias de navios: 1 . os de serviço governamental e não-comercial (independentemente de serem de natureza militar ou civil); 2 . os de serviço de comércio (independentemente de pertencerem a particulares ou a governos, ou afretados na totalidade pelo Estado).

Acolhendo as categorias recentes sem abdicar da antiga terminologia, as Convenções de Genebra de 1958 perfilham duas classificações. A primeira distingue navios de comércio ${ }^{35}$ e navios de Estado (sejam ou-não navios de guerra). ${ }^{36}$ A segunda classificação distingue navios destinados a fins comerciais $^{37}$ e os destinados a fins não-comerciais. ${ }^{38}$

A Convenção das Nações Unidas sobre o Direito do Mar tem o mérito de retomar com ortodoxia a classificação aprovada pelo Institut de Droit International. Segundo a Convenção, são duas as categorias de navios: 1. os navios mercantes e navios de Estados utilizados para fins comerciais (Parte II, Subseção B,

33. A passagem de Pitt Corbett está reproduzida em Marcel Sibert, ibidem.

34. Annuaire de l'Institut de Droit International, 1928, pp. 746 e ss.

35. Convenção sobre Mar Territorial, subseção B (arts. 18 a 20).

36. Ibidem, subseções C e D (arts. 21 a 23).

37. Ibidem, subseções A e B (arts. 14 a 20), além do art. 21.

38. Ibidem, subseções A (arts. 14 a 16), além dos arts. 19, 22 e 23 (este último com pertinência aos navios de guerra). 
arts. 27 e 28); 2. os navios de guerra e outros navios de Estado utilizados para fins não-comerciais (Parte II, Subseção C, arts. 29 a 32 inclusive).

13. Desses navios, um deles foi definido na Convenção de Genebra sobre Alto-Mar. "Para efeito" da mesma Convenção, a expressão "navio de guerra" reza o $\S 2^{\circ}$ do art. $8^{\circ}$ "designa um navio pertencente à marinha de guerra de um Estado e que traga os sinais exteriores distintivos dos navios de guerra de sua nacionalidade" "O comandante" aduz o mesmo parágrafo "deve estar a serviço do Estado; seu nome deve figurar na lista de oficiais da frota militar e a respectiva tripulação deve estar submetida a regras de disciplina militar"

A Convenção das Nações Unidas sobre o Direito do Mar traz três inovações principais a respeito dessa definição. A primeira consiste na substituição do termo "marinha de guerra" por "navio que faça parte das forças armadas do Estado". Justifica-se a alteração porque o navio de guerra pode estar a serviço de forças armadas que não a da Marinha de Guerra. A segunda inovação consiste na adoção do termo "lista de oficiais da frota militar" em vez de "lista de oficiais ou um outro documento equivalente" A segunda alteração se justifica pela sua maior abrangência. Enfim, a terceira modificação diz respeito ao contexto em que a definição se insere: a Convenção sobre o Alto-Mar, no sistema das Convenções de Genebra de 1958; e a Parte sobre o Mar Territorial na Convenção das Nações Unidas sobre o Direito do Mar. Justifica-se a inovação à medida que não há mais diversas senão uma só Convenção; que a Parte relativa ao mar territorial se localiza no início da recente Convenção; e que, finalmente, o conceito de "navio de guerra" interessa a todos os espaços oceânicos.

14. Tendo por base a terminologia empregada na Convenção de 1982, os navios de Estado podem ser de duas espécies: 1. os utilizados para fins comerciais; 2. os utilizados para fins não-comerciais. Estes últimos, por sua vez, se classificam em duas categorias: 1 . os de guerra; 2 . os que não são de guerra.

Entre os navios de Estado utilizados para fins não-comerciais e que não sejam navios de guerra, pode-se distinguir os navios encarregados: a. de funções de supervisão e de controle (polícia, alfândega, saúde); b. de serviços de manutenção e limpeza das vias marítimas (navios-dragas, quebra-gelos, os incumbidos do serviço de faróis e de balizas); c. de funções científicas (navios-escolas, navios oceanográficos). 


\section{Conceito de Nacionalidade dos Navios}

15 .

A regra de que todo navio possui nacionalidade tem suscitado alguma controvérsia na doutrina. Embora hoje tenha amplo respaldo consuetudinário e convencional, ela foi considerada no século passado por Pinheiro Ferreira como não sendo obrigatória em alto-mar, tendo em vista que nessa área vinga o princípio da liberdade dos mares. Ao próprio conceito de nacionalidade dos navios opuseram-se, na década de 1920; A. Pillet e J.P Niboyet por entenderem que a nacionalidade é um vínculo entre o Estado e seu cidadão e não entre o Estado e uma cousa. Estimavam que o navio deveria possuir apenas um pavilhão, "signe du pays qui exerce sur ses occupants la protection diplomatique et même la souveraineté personnelle" ${ }^{39} \mathrm{Tal}$ é igualmente, como acima se disse, o pensamento de Roger Pinto. A posição dominante na doutrina, contudo, se manifesta em favor da utilização desse conceito, o qual já no dizer de Próspero Fedozzi em seu curso da Haia de 1925 - "est considerée comme tellement essentielle qu'on adopte en général des mesures de tutelle très rigoureuses" 40

16. De qualquer modo, é sobretudo no costume internacional que a noção de nacionalidade de navios tem respaldo jurídico, embora tivessem variado no tempo os critérios de outorga dessa nacionalidade. O English Navigation Act, promulgado por Cromwell em 1651, exigia como requisitos para a concessão a um navio da nacionalidade inglesa, que os proprietários da embarcação e a maioria da tripulação fossem ingleses e que o navio fosse construído na Inglaterra. Critério mais liberal foi o adotado pela Odonnance de la Marine Française, ou seja, baseado na composição da tripulação. A liberalidade desse critério foi, porém, abandonada em tratados, como o de Amizade, Navegação e Comércio entre a França e o Brasil, de 1826, segundo o qual a nacionalidade dos navios franceses era a determinada pela legislação daquele país, enquanto que a nacionalidade dos navios brasileiros era prescrita pelo próprio tratado, a saber, nesse caso específico, serem construídos ou possuídos por cidadãos brasileiros e terem o capitão e $3 / 4$ da tripulação brasileira. A partir desse mesmo ano, porém, tendo por modelo a convenção então assinada pela Suécia, Noruega e pela Dinamarca, emergiu prática internacional pela qual a

39. Manuel de Droit International Privé, 1928, pp. 65-6.

40. Recueil des Cours de l'Académie de Droit International, 1925, t. V, p. 47. 
nacionalidade dos navios era, nos próprios termos dos tratados, a determinada pela legislação do Estado do pavilhão.

17. A regra consuetudinária da nacionalidade dos navios ficou robustecida com a sua incorporação definitiva no sistema das Convenções de Genebra de $1958^{41}$ assim como no da Convenção das Nações Unidas sobre o Direito do Mar, de $1982 .{ }^{42}$ Persistiram, no entanto, discrepâncias entre as legislações sobre as condições nelas exigidas para a outorga da nacionalidade a navios. De acordo com o relatório do Secretariado da UNCTAD, publicado em março de 1977, era possível, todavia, reduzir essas legislações a três sistemas básicos: 1. o daquelas, em número aliás restrito, que exigem seja a propriedade do navio inteira ou substancialmente nacional, assim como sejam nacionais o comandante e os membros da tripulação desse navio; 2. o daquelas, em maioria, que demandam esteja a propriedade do navio, em grande parte, em mãos de nacionais do país do pavilhão e sejam também nacionais desse país o comandante e uma certa proporção de oficiais (embora não necessariamente a tripulação); 3. enfim o daquela legislação de um pequeno número de países (Bahamas, Bermudas, Chipre, Libéria, Panamá, Singapura e Somália), providos de registro aberto aos estrangeiros em forma idêntica ou similar aos nacionais do país.

18. São três as ordens de interesses que motivam essa regra tanto convencional quanto consuetudinária.

Em primeiro lugar, o interesse do próprio navio, seu proprietário, sua tripulação. $\mathrm{O}$ vínculo de nacionalidade confere ao navio vantagens não-extensivas a estrangeiros (navegação de cabotagem e direito de pesca, por exemplo) e the permite, outrossim, usufruir da intervenção protetora de seu próprio Estado. Interesse também desse Estado, em segundo lugar, tanto em nível estratégico quanto econômico e político. Estratégico, porque mais poderoso é o Estado quanto maior for a sua frota, quer de guerra, quer mercante. Econômico, porque os navios, em princípio, utilizam mão-de-obra do Estado a que se vinculam e carream para ele recursos advindos de sua atividade. Político, de vez que o Estado prolonga até os seus navios, onde quer que se encontrem, o seu próprio sistema legal e a soma de poderes de que está investido.

41. Convenção sobre o Alto-Mar: art. 5 e 23 (1); Convenção sobre o Mar Territorial e a Zona Contigua: arts. 16 (3) (4); 18; 19 (1, 3 e 5); 20 (1 e 3).

42. Cf. Arts. 91; 21 (2); 26 (1); 131; 27; 28; 73 (4); 53 (1); 40; 42 (2); 42 (4); 21 (4); 22 (1); 24 (1); $25(30) ; 52(2) ; 211(3) ; 211(4) \ldots$ 
A terceira ordem de interesse que motiva a regra da nacionalidade dos navios se assenta no propósito da comunidade internacional de implantar nos mares um sistema eficaz de distribuição e aplicação das normas jurídicas no âmbito do qual se equacionem soluções adequadas a pretensões legítimas de todos os Estados. Tal propósito encontra ressonância em todos os espaços marítimos, tanto em tempo de paz quanto em tempo de guerra. Em relação ao alto-mar essa ressonância parece alcançar especial vigor em razão da ausência nele de toda soberania ${ }^{43}$ e do princípio nele vigente da liberdade dos mares. Em consonância com esse princípio é que se consagrou a regra da "proibição da interferência de todo pavilhão na navegação em tempo de paz de qualquer outro pavilhão"44 e desde que, de fato, inexista "uma convenção especial" ${ }^{, 45}$ a respeito. Essa ausência de soberania não impede, todavia, a um Estado, como se sabe, de exercer interferência que julgue oportuna no trânsito de seus próprios navios.

\section{Regras sobre Nacionalidade dos Navios}

20.

As três ordens de interesses a que estamos a nos referir nos permitem compreender o surgimento de determinadas normas consuetudinárias que, revigoradas pelo direito convencional, concernem a nacionalidade de navios. Uma dessas normas é a que todos os Estados, "sean ribereños o sin litoral, tiénen el derecho de que los buques que enarbolan su pabellón naveguen en alta mar" 46 Outra norma é a que veda a esses Estados “cambiar de pabellón durante un viaje ni en una escala, excepto como resultado de um cambio efectivo de propriedad o en su registro" 47

Anteriormente à conclusão da Convenção de Genebra sobre Alto-Mar e mesmo no curso da Primeira Conferência das Nações Unidas sobre o Direito do Mar (1958), suscitava-se a questão de saber se poderia ter o navio uma segunda

43. Cour Permanente de Justice Internationale, Publications, Ser. A, n. 20, p. 25.

44. Doc. A./CN.4/32, Annuaire de la Commission du Droit International, 1950-П, pp. 69 e ss.

45. Cf. Sentença de 2 de dezembro de 1921, sobre as embarcações Jessie, Thomas F. Bayard e Pescawha, Recueil des sentences arbitrales internationale, N.V., VI, p. 58.

46. Art. 40 da Convenção de Genebra sobre Alto-Mar (1958) e art. 90 da Convenção das Nações Unidas sobre o Direito do Mar (1982).

47. Art. $6^{\circ}, \S 1^{\circ}$, da Convenção de Genebra sobre Alto-Mar (1958) e art. $92, \S 1^{\circ}$, da Convenção das Nações Unidas sobre o Direito do Mar (1982). 
nacionalidade. A delegação do Reino Unido esposava essa idéia, inspirada, por certo, no desejo de que os navios dos Domínios mostrassem a sua relação com a Comunidade Britânica das Nações.

Ainda quanto à nacionalidade dos navios, aduzem-se duas regras consuetudinárias e igualmente convencionais. A primeira norma, já estipulada na Convenção de Genebra sobre Alto-Mar (1958), ${ }^{48}$ é a de que cada Estado "establecerá los requisitos necesarios para conceder su nacionalidad a los buques, para su inscripción en un registro en su território y para que tengan el derecho de enarbolar su pabellón" ${ }^{49}$ A segunda norma, enfim, é a que estabelece que cada Estado "expedirá, para los buques a los que haya concedido el derecho de enarbolar su pabellón, los documentos procedentes" 50

\section{A Questão do Vínculo Substancial}

21. As três ordens de interesses a que estamos a nos referir, nos permitem compreender o surgimento de determinadas regras consuetudinárias que, tal como as quatro acima referidas sobre nacionalidade, foram revigoradas pelo direito convencional. Entre essas normas está a de que deve existir "una relación auténtica entre el Estado y el buque" 51

22. Até a sentença da Corte Internacional de Justiça, proferida na questão Nottebohm, ${ }^{52}$ se afirmava, assim, o princípio da competência exclusiva do Estado em outorgar nacionalidade a um navio e em fixar as regras concernentes a esse princípio. Foi o que ficara consagrado na sentença sobre o navio Montijo, de $1875^{53}$ e sobre a controvérsia dos Boutres de Mascate, de 08 de agosto de $1905 .^{54}$

48. Art. $5^{\circ}, \S 1^{\circ}, 1^{\mathrm{a}}$ alínea.

49. Art. $91, \S 1^{\circ}, 1^{\mathrm{a}}$ alínea, da Convenção das Nações Unidas sobre o Direito do Mar (1982).

50. Art. $5^{\circ}$, § $2^{\circ}$, da Convenção de Genebra sobre Alto-Mar (1958) e art. $91, \S 2^{\circ}$, da Convenção das Nações Unidas sobre o Direito do Mar (1982).

51. Art. $5^{\circ}, \S 10,3^{\mathrm{a}}$ alínea, da Convenção de Genebra sobre Alto-Mar (1958) e art. $90, \S 1^{\circ}, 3^{\mathrm{a}}$ alínea da Convenção das Nações Unidas sobre o Direito do Mar (1982).

52. C.I.J., Recueil des arrêts, 1955, pp. 4 e ss.

53. Vide texto da sentença in J.B. Moore, History and Digest of the international arbitrations to which the United States has been a party, 1898, p. 1433.

54. Clunet, 1906, pp. 1289 e ss. 
Dada essa competência própria e exclusiva, alguns Estados passaram a outorgar, ainda no curso da Primeira Guerra Mundial, de modo extremamente liberal, seu pavilhão a navios que aparentemente estariam sob controle estrangeiro. Assim, desde 1916, o Panamá passou a favorecer companhias do país controladas por acionistas estrangeiros. ${ }^{55}$ Fizeram o mesmo, a seguir, a Libéria, e, em menor escala, Honduras e Costa Rica. ${ }^{56}$ Inconvenientes diversos emergiam do sistema de pavilhões de conveniência, entre os quais estava o da infringência de normas internacionais trabalhistas, razão pela qual, graças à pressão exercida, logo após a Segunda Guerra Mundial, pela International Transport Workers Federation (ITF) e armadores europeus, sobretudo britânicos e escandinavos, se reuniu, sob os auspícios da OIT, a conferência de 1949, de que surgiam recomendações corretivas dos navios de conveniências, em particular dos panamenhos. Desde então, a questão dos pavilhões de conveniência se tornou crucial na temática da nacionalidade dos navios. 23. A intensificação da prática dos navios de conveniência logo após a Segunda Guerra Mundial se deu ao ensejo da venda pelos Estados Unidos de grande quantidade de cargueiros, sobretudo os do tipo Liberty construídos durante o conflito armado. Grupos compradores, constituídos por armadores da nacionalidade do país de venda, desejavam livrar-se da influência dos sindicatos desse país que exigiam salários reputados mui altos. Outros grupos compradores, compostos de armadores gregos, receavam que eventual passagem do governo de Atenas para a esfera socialista determinasse a expropriação dos navios que possuíssem. Ambos os grupos procuravam, então, países seguros e pouco exigentes que, por taxas módicas, autorizassem o registro dos navios sob suas bandeiras.

24. Embora a questão Nottebohm estivesse circunscrita a preceitos sobre nacionalidade de pessoa física, a sentença da Corte que a dirimiu teve repercussão, por via de analogia, na temática da nacionalidade dos navios. É conhecida a controvérsia. Cidadão de origem alemã, nascido em 1881 de pais alemães na cidade de Hamburgo, se transferiu em 1905 para a Guatemala onde se domiciliou. Nottebohm permaneceu alguns meses a partir de março de 1939 no Liechtenstein, cuja nacionalidade então obteve, antes de retornar à Guatemala. Proclamado o estado de guerra em 194.1 entre este país e a Alemanha, Nottebohm foi detido pelas

55. Cf. Rodney P. Carlisle, Sovereignty for Sale, Annapolis, Naval Institute Press, 1981, p. 11.

56. Como se sabe, reformas adotadas pelo governo da Costa Rica em 1958 conduziram à abolição do registro aberto em 1962. 
autoridades guatemaltecas, permaneceu internado nos Estados Unidos até 22 de janeiro de 1946 e teve seus bens na Guatemala confiscados. Uma vez libertado, instalou-se definitivamente no Liechtenstein, país este que, a 10 de dezembro de 1951, ajuizou ação perante a Corte Internacional de Justiça para o fim de obter reparação dos danos causados a seu recente cidadão, alegando transgressão do direito das gentes. Como se sabe, a Corte se manifestou contrariamente à pretensão do Liechtenstein com base na inexistência de elo que vinculasse genuinamente Nottebohm a esse país e no reconhecimento, ao contrário, de elo antigo e estreito entre o mesmo cidadão e a Guatemala. Após mencionar ter a naturalização no Liechtenstein sido pleiteada com o fim de obter a proteção eventual de um Estado neutro em caso de guerra, a Corte concluiu que a Guatemala "não estava obrigada a reconhecer uma nacionalidade assim outorgada" e que, por conseguinte, o Liechtenstein não tinha o direito de estender, em face da Guatemala, a sua proteção a Nottebohm. ${ }^{57}$

25. A exigência de vínculo substancial entre a pessoa física e o Estado de que se pretenda a nacionalidade não tardou a se projetar na temática da nacionalidade dos navios. O requisito desse vínculo se inscreveu na Convenção de Genebra sobre Alto-Mar, concluída três anos depois da sentença Nottebohm, ou seja, a 29 de abril de 1958. Nos termos da Convenção, cabe ao Estado fixar "as condições segundo as quais confere a sua nacionalidade aos navios e lhes concede matrícula e o direito de arvorar a sua bandeira". Deve existir, porém, aduz a Convenção, um "vínculo substancial"58 entre o Estado e o navio. Ao Estado compete o dever de "exercer principalmente, de modo efetivo, jurisdição e controle nos planos técnico, administrativo e social, sobre os navios que arvorem a sua bandeira" (art. $5^{\circ}, \S 1^{\circ}$ ).

No mesmo ano da assinatura da Convenção, o requisito da substancialidade do vínculo ficou reafirmado em duas resoluções da OIT concernentes ao trabalho marítimo.

57. Sobre a sentença Nottebohm, ver Paul de Visscher, RGDIP, 1956, pp. 238-266 e FrançoisMichel Fay, ob. cit., pp. 1015-6.

58. O princípio do "vínculo substancial" não chegou a ser proposto pela Comissão de Direito Internacional, à qual fora cometida a tarefa de codificação que precedeu a convocação da Primeira Conferência das Nações Unidas sobre Direito do Mar. Proposto esse princípio no próprio âmbito da Conferência, foi ele aprovado, após acirrados debates, na Segunda Comissão, por 40 votos contra 7 e 11 abstensão. Todavia parece que o termo "genuine link" decorre de uma proposta apresentada a 16 de março de 1956 à Comissão de Direito Internacional pelo governo holandês, que se referira nessa oportunidade ao Caso Nottebohm (Geoffrey Marston, ob. cit., p. 575). 
26.

Sofreu esse requisito, porém, vicissitudes a seguir. Abalou-o o parecer consultivo da Corte Internacional de Justiça, de 8 de junho de 1960, relativo à composição do Comitê de Segurança Marítima da Organização Internacional Consultiva de Navegação Marítima (IMCO). Tratava-se de interpretar a regra da alínea $a$ do art. 28 da convenção constitutiva do Comitê, o qual nos termos dessa disposição "se compõe de quatorze membros eleitos pela Assembléia Geral entre os membros, governos dos países que têm um interesse importante nas questões de segurança marítima", sendo que oito pelo menos desses países "devem ser os que possuem as frotas de comércio mais importantes..." Qual o critério de tonelagem dos navios para identificar esses países: o da tonelagem referente apenas aos nacionais do Estado do pavilhão, ou da referente aos navios matriculados nesse mesmo Estado? O parecer da Corte, de 8 de junho de 1960, optou, como se sabe, pela segunda dessas alternativas, contrariando, pois, a tese da substancialidade do vínculo de nacionalidade. Foi ponderado, todavia, que o tribunal deixara de levar em conta as disposições pertinentes do art. $5^{\circ}$ da Convenção de Genebra sobre o AltoMar pelo fato de, ao proferir a sentença, não haver ainda a Convenção entrado em vigor. ${ }^{59}$ Não há negar, porém, que mesmo após a vigência desse tratado, decisão da Suprema Corte dos Estados Unidos no caso Incres-Hondurenha, negou jurisdição às autoridades governamentais sobre navios de bandeira estrangeira, mesmo de bandeira de conveniência, surtos em portos do país. Interesses econômicos estimulavam o crescimento de frota mercante liberiana que, em 1966, se tornou a maior do mundo.

27. Porém, reação foi suscitada contra essas decisões, em particular contra o parecer consultivo da Corte, ${ }^{60}$ motivada ademais por fatores econômicos, políticos, fiscais assim como ecológicos. Essa derradeira motivação decorreu de uma série de acidentes ocorridos com navios de conveniência, resultantes das circunstâncias precárias em que operavam e acarretadores de prejuízos graves ao meio ambiente. Nessa série de acidentes se incluíam os ocorridos com o petroleiro liberiano Torrey Canyon, em 1967, em Cornwall, de que resultou o derrame de 117 mil toneladas de

59. Entrada em vigor, de fato, a 30 de setembro de 1962, ou seja, mais de dois anos após a publicação da sentença da Corte.

60. Assinalem-se os votos dissidentes dos juízes Klaestad e Moreno Quintana (C.LJ., Recueil, 1960, pp. 173 e ss.). Vide igualmente Colliard, L'avis consultatif de la CIJ sur la composition du Comité de la sécurité maritime de la OMCL, AFDI, 1960, pp. 338-61; Roux, ob. cit., pp. 75-9; Fay, ob. cit., pp. 1020-22. 
petróleo; com o Ocean Eagle, encalhado em Porto Rico, em 1968; com o petroleiro Argo Merchant, que teve lugar em 1976, em Nantucket; e com o petroleiro Amoco Cadiz, encalhado na Bretanha, em 1978, de que decorreu o derrame de 230 mil toneladas de petróleo. Esse número crescente de acidentes refletia igualmente o aumento considerável de navios de bandeira de conveniência.

28. Um ano antes do acidente com o Amoco Cadiz, o Secretariado da UNCTAD, por instâncias do Grupo B, elaborou importante relatório sobre "Conseqüências Econômicas da Existência, ou-não, de um Vínculo Genuíno entre o Navio e a Bandeira de Registro" (TD/B/C.4/168). A esse relatório três outros se sucederam, da autoria do mesmo Secretariado, tendo em vista a convocação da $\mathrm{V}$ UNCTAD (Manilha, maio de 1979).

29. Cabe notar que já a primeira UNCTAD, reunida em Genebra em 1964, havia "inserido os transportes marítimos na análise das relações entre economia internacional do desenvolvimento" ${ }^{61}$ Da segunda UNCTAD (Nova Delhi, 1968) emergiu recomendação da criação de grupo de trabalho (como órgão auxiliar da Comissão de Transportes Marítimos) sobre a regulamentação internacional desses transportes. Das atividades iniciais desse grupo, que se dedicou à questão da revisão da Convenção Internacional de 1924 sobre a unificação de certas regras em matéria de conhecimentos (regras da Haia), emergiram finalmente, a longo prazo, as regras de Hamburgo, ou seja, da Convenção das Nações Unidas sobre o transporte de mercadorias por mar, de 1978. Outra relevante contribuição da UNCTAD foi a Convenção relativa a um código de conduta das conferências marítimas.

30. Como corolário de manutenção do tema das consequiências econômicas de vínculo genuíno entre o navio e a sua bandeira na agenda da UNCTAD subseqüente à reunião de Manila (maio de 1979), ${ }^{62}$ teve lugar de 1982 a 1984 a Conferência de Plenipotenciários, cuja finalidade foi a de elaborar a Convenção sobre as Condições de Registro de Navios, destinada a consagrar os

61. Paul Berthoud, Les transports maritimes dans le dialogue nordud. Aspects Actuels du Droit International des Transports Société française pour le Droit international, Colloque du Mans, Paris, Pedone, 1981, p. 44. É certo que dezesseis anos antes, a Conferência Marítima das Nações Unidas, de Genebra, 1948, elaborara a convenção constitutiva da OMCI, que entrou em vigor em 1958, ensejando o início dessa organização em 1959. Mas, como lembra o autor, a OMCI deveria apenas cuidar dos aspectos técnicos e de segurança da navegação marítima e não dos aspectos econômicos (ibidem, n. 45).

62. Sobre o processamento das negociações relativas ao vínculo genuíno no âmbito da UNCTAD, cf. Paul Berthoud, ob. cit., pp. 61-7. 
elementos mínimos de um "vínculo genuíno" que deve existir entre o navio e o Estado, cuja bandeira ele arvora. Durante os debates, controvérsia emergiu entre, de um lado, Estados em desenvolvimento do Grupo de 77, para os quais o "vínculo genuíno" requer sejam nacionais do Estado de registro proprietários, tripulação e comandantes; e de outro lado, Estados desenvolvidos, do Grupo B, para os quais tais requisitos de nacionalidade não conduziriam a nenhum aperfeiçoamento de segurança, controle e efetividade de navegação internacional e para os quais, embora tais requisitos existissem em algumas legislações, não foram eles suficientes para gerar a esse respeito nenhuma regra de Direito Internacional. ${ }^{63} \mathrm{O}$ art. $8^{\circ}$ da Convenção exprime, outrossim, uma certa conciliação entre as teses de ambos os grupos, ao prescrever que o Estado de pavilhão deve contemplar "disposições adequadas" sobre a participação de seus nacionais como proprietários e sobre o nível dessa participação; e que essas disposições devem ser suficientes "para permitir ao Estado de pavilhão o exercício efetivo de sua jurisdição e controle sobre os navios que arvoram esse pavilhão".

31. A Convenção apresenta, outrossim, novos padrões de responsabilidade para a indústria naval internacional e busca harmonizar normas estatais concernentes ao registro de navios.

Um desses padrões remete à noção de "administração nacional marítima" definida pela Convenção como sendo "a autoridade ou organismo estatal, estabelecido pelo Estado de registro em conformidade com a sua legislação e que, segundo essa legislação, é responsável, inter alia, pela implementação de acordos internacionais concernentes ao transporte marítimo e pela aplicação de regras, e padrões relativos a navios sob a sua jurisdição e controle" (art. $2^{\circ}$ ). Cada Estado deve ter uma administração nacional marítima, sujeita a sua jurisdição e controle, administração essa obrigada a adotar normas e exercer controle sobre o registro de navios (art. $5^{\circ}$ ). $\mathrm{O}$ registro do navio assim como os livros de bordo (logbooks) devem conter dados os mais completos e pormenorizados, de modo a permitir a identificação e responsabilidade de proprietários e operadores de navios (arts. $6^{\circ}$ e 11). Ademais, cabe a inspetores autorizados do Estado inspecionarem periodicamente os navios de respectivo pavilhão para o fim de "assegurar o respeito das regras e normas internacionais aplicáveis” (art. $5^{\circ}, \S 3^{\circ}, b$ ). 
Quanto à entrada em vigor da Convenção, determinou-se o período de doze meses depois da data em que não menos do que quarenta Estados, cujas tonelagens somadas representam pelo menos $25 \%$ da tonelagem mundial, se tenham tornado Partes Contratantes, o que pode ocorrer: a. por via de assinatura não sujeita à ratificação, aceitação ou aprovação; b. por via de assinatura sujeita à ratificação, aceitação ou aprovação; ou c. por via de adesão.

32. Tendo em vista a definição de navio (embarcações registradas com mais de quinhentas tonelagens brutas), a relação dos países constante do Anexo III da Convenção indica que, no momento da assinatura desse tratado, os países de maior tonelagem bruta são precisamente dois países de registro aberto, a Libéria e o Panamá, respectivamente com 57.985.747 e 39.366.187 tonelagem bruta. Visando a estabelecer novas condições para o registro de embarcações, a Convenção está a promover a mudança do seu próprio Anexo III e a implantar, ao mesmo tempo, como se verifica novas regras a respeito da nacionalidade dos navios.

\section{Observações Finais}

33. Como acima se notou, toda solução a se propor ao conflito de leis marítimas exige o exame de questões prévias, a começar pelo estudo do problema da nacionalidade dos navios, o qual, por sua vez, demanda a análise da questão do conceito e da classificação dos navios. Toda essa temática variada e complexa tem sofrido o influxo de mudança de costumes e de convenções internacionais, das quais as mais recentes e fundamentais são a Convenção das Nações Unidas sobre o Direito do Mar, de 10 de dezembro de 1982, e a Convenção sobre Condições de Registro de Navios, de 7 de fevereiro de 1986. As dificuldades no exame do conflito de leis marítimas e das questões prévias respectivas se acentuam pelo fato de que regras de direito colisional nem sempre se localizam em tratados de Direito Internacional Privado, mas, ao contrário, se inserem, com freqüência cada vez maior, em tratados de índole diversa, como os dois supramencionados. Como se verificou, a definição de navio só tem sido possível desde que revestida de caráter ad hoc, segundo aliás o atesta a Convenção sobre Condições de Registro de Navios, há pouco celebrada. Quanto à classificação de navios, observou-se que a mudança dos critérios respectivos se encontra refletida na Convenção de Montego Bay, de 1982. 
34. Ciente dos escolhos e inconvenientes de uma definição de navio, Haroldo Valladão buscou evitá-la em seu Anteprojeto oficial de reforma da Lei de Introdução ao Código Civil. Quanto à condição dos navios os assemelha às aeronaves ao estipular no art. 45 de seu Anteprojeto considerarem-se "situados em território do Estado de sua nacionalidade os navios e aeronaves militares onde quer que se encontrem, e os de outra espécie quando em alto-mar ou em território que não pertença a nenhum Estado"

No conteúdo desse artigo, constam duas outras questões prévias a todo conflito de leis marítimas: a da classificação e a da nacionalidade dos navios. Em relação a essa derradeira questão que, segundo acima se apontou, tem alcançado na atualidade profunda e merecida ressonância, Haroldo Valladão propôs duas normas que se harmonizam com as diretrizes estipuladas nas convenções internacionais recentes sobre a matéria. Consoante uma dessas normas, "os direitos reais e os privilégios de ordem privada sobre os navios e as aeronaves regem-se pela lei de sua nacionalidade" (art. 46). Consoante outra norma, "a mudança de nacionalidade não prejudica os direitos adquiridos" (parágrafo único do mesmo artigo).

São Paulo, dezembro de 1995. 